See Article page 1784 .

\section{Commentary: Moderate aortic regurgitation at the time of surgery: Just don't do it}

\author{
Dimitri Kalavrouziotis, MD, FRCSC, and \\ Siamak Mohammadi, MD, FRCSC
}

Aortic valve (AV) repair or replacement for moderate aortic regurgitation (AR) is a reasonable option (class IIa) in patients undergoing cardiac surgery for indications other than the $\mathrm{AV}$ in the latest iteration of the guidelines of the American College of Cardiology/American Heart Association. ${ }^{1}$ On the other side of the pond, this recommendation is slightly less enthusiastic, and AV intervention in this setting is largely dictated by the status of the aortic root and ascending aorta. ${ }^{2}$ Guidelines were essentially based on expert opinion and informed by a sparse literature showing that progression of $\mathrm{AR}$ is rare in the absence of significant $\mathrm{AV}$ leaflet pathology and aortic root or ascending aortic dilation. $^{3}$

In this issue of the Journal, Ward and colleagues ${ }^{4}$ attempt to determine the prevalence and progression of moderate $\mathrm{AR}$ in a cohort of patients referred for coronary artery bypass graft surgery (CABG), mitral valve surgery, and aortic aneurysm repair in a single-center retrospective dataset. The prevalence of moderate AR was low $(\mathrm{n}=138$ of 3289 patients; $4.2 \%$ ); approximately one-third of the patients were treated with either AV repair or AV replacement without an increase in operative risk, while the remaining patients with moderate AR had no intervention on the AV. At a median follow-up of 6 years, a greater severity of preoperative AR was associated with diminished late survival. However, the progression to $>2+\mathrm{AR}$ was extremely rare $(<3 \%)$, as was the rate of late reoperation. These findings

From the Division of Cardiac Surgery, Quebec Heart and Lung Institute, Quebec City, Quebec, Canada

Disclosures: The authors reported no conflicts of interest.

The Journal policy requires editors and reviewers to disclose conflicts of interest and to decline handling or reviewing manuscripts for which they may have a conflict of interest. The editors and reviewers of this article have no conflicts of interest.

Received for publication Dec 29, 2020; revisions received Dec 29, 2020; accepted for publication Dec 30, 2020; available ahead of print Jan 9, 2021.

Address for reprints: Siamak Mohammadi, MD, FRCSC, Division of Cardiac Surgery, Quebec Heart and Lung Institute, 2725 chemin Sainte-Foy, Quebec City, QC, Canada, G1V 4G5 (E-mail: siamak.mohammadi@fmed.ulaval.ca).

J Thorac Cardiovasc Surg 2022;164:1794-5

$0022-5223 / \$ 36.00$

Copyright (c) 2021 by The American Association for Thoracic Surgery

https://doi.org/10.1016/j.jtcvs.2020.12.136
Check for updates

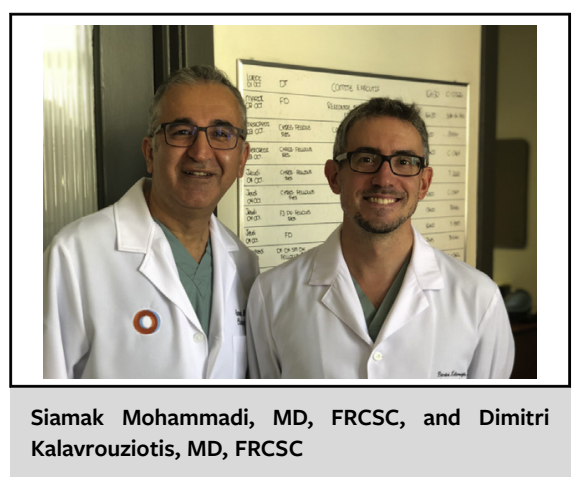

CENTRAL MESSAGE

Most moderate aortic regurgita-

tion at the time of cardiac sur-

gery can be left alone, although

the determinants of progression

need to be elucidated using an

integrated imaging approach at

follow-up.

were similar after risk adjustment using propensity scores. The curves showing the late freedom from $>2+A R$ and $\mathrm{AV}$ intervention were largely superimposable when patients were stratified according to severity of preoperative AR. The authors concluded that repairing or replacing the AV for moderate AR at the time of cardiac surgery for other indications is safe. However, leaving the $\mathrm{AV}$ alone is also a defensible position, as there is no late mortality impact, and progression to more severe $\mathrm{AR}$ is the exception rather than the rule.

The study is laudable for including late echocardiographic data, as the sole reliance on clinical data (eg, late death, reoperation) as a surrogate for longitudinal outcome analysis may underestimate the true risk of progression of valvular disease. However, the likelihood of finding AR depends on how hard one looks for AR. It is unclear whether late echocardiography was performed at the authors' institution or in less experienced centers and whether transesophageal echocardiography was used in equivocal cases. The extent to which semiquantitative (eg, vena contracta width, pressure half-time) and quantitative (eg, effective regurgitant orifice area, regurgitant volume) echocardiographic parameters were considered also is not stated. If the echocardiographic measurements are suboptimal, an integrated approach using cardiac magnetic resonance imaging can provide an accurate 
assessment of regurgitant volume and fraction, and it has the added benefit of measuring left ventricular volume and systolic function along with AV morphology. Unfortunately, this dimension was not explored by the authors. Another limitation of the study is the heterogeneity of the patient population, as CABG patients were included alongside mitral valve surgery patients and aortic aneurysm repair patients. It is not surprising that the likelihood of intervening on the $\mathrm{AV}$ is influenced by whether the surgeon plans on opening the cardiac chambers; CABG patients had a significantly higher probability of leaving the operating room without $\mathrm{AV}$ intervention.

There are other factors that clearly influence the decision to intervene on the AV, as reported by the authors, who showed an increased probability of repairing or replacing the $\mathrm{AV}$ in the presence of leaflet abnormalities (eg, bicuspid AV, rheumatic valve disease). However, the study lacks granularity with respect to the mechanism of AR, especially in the patients without ascending aortic or root disease, and although centricity of the jet was reported, no data are provided on the functional anatomic aspects of the $\mathrm{AV}^{5}$ A combination of integrated comprehensive imaging and a nuanced anatomic functional description of $\mathrm{AV}$ dysfunction may have allowed for the elaboration of an algorithm for the management of moderate AR during cardiac surgery (similar to that used for the assessment and management of mitral regurgitation), and would have greatly enhanced the quality of the study.

Ultimately, the decision to repair/replace or leave the AV alone was made by the operating surgeon, and no amount of multivariable analysis can adjust out the confounding associated with the "individual surgeon" variable. The study by Ward and colleagues, although unlikely to influence current clinical practice guidelines, demonstrates that patient selection is crucial, and that excellent early and late results can be achieved when the right procedure is performed on the right patient.

\section{References}

1. Otto CM, Nishimura RA, Bonow RO, Carabello BA, Erwin JP, Gentileet F, et al 2020 ACC/AHA guideline for the management of patients with valvular heart disease: a report of the American College of Cardiology/American Heart Association Joint Committee on clinical practice guidelines. J Am Coll Cardiol. 2021;77: e25-197.

2. Baumgartner H, Falk V, Bax JJ, De Bonis M, Hamm C, Holm PJ, et al. 2017 ESC/ EACTS guidelines for the management of valvular heart disease. Eur Heart J. 2017;38:2739-91.

3. Weisenberg D, Omelchenko A, Shapira Y, Vaturi M, Monakier D, Bental T, et al. Mid-term echocardiographic progression of patients with moderate aortic regurgitation: implications for aortic valve surgery. J Heart Valve Dis. 2013;22:192-4.

4. Ward A, Malaisrie SC, Andrei AC, Bonow RO, Thomas JD, Puthumana J, et al Fate of moderate aortic regurgitation after cardiac surgery. J Thorac Cardiovasc Surg. 2022;164:1784-92.e1.

5. Le Polain de Waroux JB, Pouleur AC, Goffinet C, Vancraeynest D, Van Dyck M, et al. Functional anatomy of aortic regurgitation: accuracy, prediction of surgical repairability, and outcome implications of transesophageal echocardiography. Circulation. 2007; 116:I264-9. 